\title{
Differential Effects of Protein Synthesis Inhibition on the Activity- Dependent Expression of BDNF Transcripts: Evidence for Immediate-Early Gene Responses from Specific Promoters
}

\author{
Julie C. Lauterborn, ${ }^{1,2}$ Santiago Rivera, ${ }^{1}$ Curtiss T. Stinis, ${ }^{1}$ Valerie Y. Hayes, ${ }^{3}$ Paul J. Isackson, ${ }^{3,4}$ and \\ Christine M. Gall 1,2 \\ Departments of ${ }^{1}$ Anatomy and Neurobiology and ${ }^{2}$ Psychobiology, University of California, Irvine, California 92697-1275, \\ and Departments of ${ }^{3}$ Molecular Neuroscience and ${ }^{4}$ Biochemistry and Molecular Biology, Mayo Clinic, Jacksonville, \\ Florida 32224
}

In the adult rat forebrain, brain-derived neurotrophic factor (BDNF) expression is very rapidly induced by neuronal activity, suggesting that this might occur without intervening protein synthesis. The rat $B D N F$ gene has four differentially regulated promoter regions; each gives rise to an mRNA containing a unique $5^{\prime}$ exon (I-IV) and a common $3^{\prime}$ exon (V) that codes for mature BDNF protein. The present study used exon-specific in situ hybridization and both in vivo and in vitro preparations to determine whether activity induces BDNF as an "immediateearly gene" (IEG) from specific promoter regions and to compare the regulation of BDNF and nerve growth factor (NGF). In cultured hippocampal slices, kainic acid markedly increased pan-BDNF (exon V) and NGF mRNA content; cycloheximide attenuated the effect of kainic acid on both. In vivo stimulation of a paroxysmal afterdischarge increased both pan-BDNF and
NGF mRNA levels in the dentate gyrus granule cells; pretreatment with anisomycin modestly attenuated the paroxysmal afterdischarge-induced increase of both transcripts. To determine whether partial drug effects on BDNF expression reflect the differential regulation of transcript species, levels of mRNAs containing exons I-IV were evaluated. A single afterdischarge increased exon I-IV-containing mRNA levels; anisomycin significantly attenuated the increase in exon I- and II-containing mRNAs but had no effect on the increase in exon III- and IV-containing mRNAs. These data show that for mature forebrain neurons, activity induces the expression of BDNF exon IIIand IV-containing transcripts as IEG responses.

Key words: brain-derived neurotrophic factor; hippocampus; nerve growth factor; cycloheximide; immediate-early gene; gene regulation
Brain-derived neurotrophic factor (BDNF) is a member of the neurotrophin family of structurally related factors (Leibrock et al., 1989) that includes nerve growth factor (NGF). BDNF is broadly and abundantly expressed in mammalian brain and through its tyrosine kinase receptor trkB (Squinto et al., 1991) has been demonstrated to support the viability and biosynthetic activities of a great diversity of central neurons (Spina et al., 1992; Ip et al., 1993; Koliatsos et al., 1993; Ghosh et al., 1994; Hyman et al., 1994; Kokaia et al., 1994b; Nakao et al., 1995). There is substantial evidence that neuronal activity, and other manipulations that increase intracellular calcium content (Lindvall et al., 1994), increase the expression of BDNF and NGF by adult neurons. In vitro, manipulations that increase depolarization or decrease inhibition, increase BDNF and NGF mRNA levels in hippocampal neurons (Zafra et al., 1991, 1992). In vivo, seizures (Gall, 1993) and subseizure stimulation of excitatory afferents (Lindefors et al., 1992; Patterson et al., 1992; Castrén et al., 1993; Dragunow et al., 1993) increase BDNF mRNA in hippocampal granule and pyra-

\footnotetext{
Received March 8, 1996; revised Aug. 1, 1996; accepted Sept. 5, 1996.

This research was supported by funding from the Mayo Foundation to P.J.I., and Grant NS26748 from the National Institute of Neurological and Communicative Disorders and Stroke, Research Scientist Development Award MH00974 from National Institutes of Health, and Faculty Award for Women Scientists and Engineers BNS9024143 from National Science Foundation awarded to C.M.G. We thank Julie Wong and Robert Berschauer for expert technical assistance.

Correspondence should be addressed to Christine M. Gall, Department of Anatomy and Neurobiology, University of California at Irvine, Irvine, CA 92697-1275.

Dr. Rivera's present address: INSERM, Unité 29, Hospital de Port Royal, 123 Boulevard de Port Royal, 75674 Paris, France.

Copyright (C) 1996 Society for Neuroscience $0270-6474 / 96 / 167428-09 \$ 05.00 / 0$
}

midal cells and NGF mRNA in granule cells alone. Moreover, seizures increase BDNF and NGF protein content (Bengzon et al., 1992; Humpel et al., 1993; Nawa et al., 1995).

NGF expression is thought to be regulated via the induction of transcriptional regulatory factors and their action at an AP-1 site in the first intron of the NGF gene (Mocchetti et al., 1989; Hengerer et al., 1990; D'Mello and Heinrich, 1991; Cowie et al., 1994). BDNF expression has not been linked to AP-1 activity. Rather, the speed of activity-dependent increases in BDNF mRNA content (e.g., within 20 min of stimulation) (Isackson et al., 1991; Gall, 1993) raises the possibility that activity may induce BDNF as an immediate-early gene (IEG) response (i.e., without intervening protein synthesis). Hughes et al. (1993) found that damage-induced increases in hippocampal BDNF mRNA content were not blocked by protein synthesis inhibition. This supports the hypothesis that BDNF can be induced as an IEG but does not indicate whether similar mechanisms are involved in the regulation of BDNF expression by neuronal activity.

The goal of the present study was to test whether activity induces BDNF expression as an IEG and, in particular, to determine whether there is differential involvement of protein synthesis in the regulation of the different BDNF mRNA species. For comparison purposes, effects on NGF mRNA levels were evaluated in the same preparations. The rat $B D N F$ gene includes four short 5' exons (exons I-IV) that are each associated with a separate promoter, and one $3^{\prime}$ exon (exon V) that encodes the mature BDNF protein (Timmusk et al., 1993; Nakayama et al., 1994). The four different promoters give rise to four predominant 
transcripts, each containing one of the $5^{\prime}$ exons in addition to exon V. Recent studies using probes specific for exons I-IV have shown that transcripts containing these exons are (1) differentially expressed across brain regions under normal circumstances (Timmusk et al., 1993; Bishop et al., 1994), and (2) differentially regulated by a variety of manipulations including changes in neuronal activity (Metsis et al., 1993; Timmusk et al., 1993; Nakayama et al., 1994). The first phase of the present study assessed the effects of protein synthesis inhibitors on expression induced by afterdischarge stimulation in vivo and by kainic acid in vitro, using cRNA probes to BDNF exon $\mathrm{V}$ and NGF mRNAs. The second phase determined whether protein synthesis inhibition had selective effects on the distinct BDNF transcripts. The results show that in distinction from BDNF exons I and II, promoters linked to BDNF exons III and IV are fully inducible in the presence of protein synthesis inhibitors, suggesting that these transcripts are regulated by activity as IEGs.

\section{MATERIALS AND METHODS}

\section{In vivo experiments}

Animal treatments. A total of 70 adult male Sprague Dawley rats (250-350 gm) (Simonsen Labs, Gilroy, CA) were used. Animals were divided into four groups. Group 1 rats $(n=16)$ were given the protein synthesis inhibitor anisomycin $30 \mathrm{~min}$ before and $30 \mathrm{~min}$ after stimulation of a single paroxysmal afterdischarge (PD) and were killed $2 \mathrm{hr}$ after the PD. Group 2 rats $(n=26)$ received PD stimulation without anisomycin treatment. Of the group 2 rats, 15 were killed $2 \mathrm{hr}$ after stimulation; the remainder were used to determine the time course of changes in BDNF mRNA content and were killed at poststimulus intervals ranging from 15 $\min$ to $2 \mathrm{hr}(n \geq 3$, per time point). Group 3 rats $(n=12)$ were given two anisomycin (Sigma, St. Louis, MO) injections $1 \mathrm{hr}$ apart and were killed $1.5 \mathrm{hr}$ after the second injection. Group 4 rats $(n=16)$ received either two subcutaneous saline injections $1 \mathrm{hr}$ apart for saline controls or no treatment and served as naive controls. Anisomycin was given at $25 \mathrm{mg} / \mathrm{kg}$ subcutaneously in all instances. Rats were killed by sodium pentobarbital overdose and intracardial perfusion with $4 \%$ paraformaldehyde in $0.1 \mathrm{M}$ phosphate buffer $(\mathrm{PB}), \mathrm{pH}$ 7.2. Brains were removed from the cranium, post-fixed overnight in the perfusate at $4^{\circ} \mathrm{C}$, placed in $4 \%$ paraformaldehyde with $20 \%$ sucrose in PB for $1-2 \mathrm{~d}$ at $4^{\circ} \mathrm{C}$, and then sectioned on a freezing microtome at a thickness of $25 \mu \mathrm{m}$. Tissue sections were processed free-floating for the in situ hybridization localization of mRNA sequences for BDNF exons I-V, c-fos, and NGF, as described below.

Electrical stimulation. A single hippocampal PD was induced by perforant path stimulation in rats anesthetized with ketamine $(50 \mathrm{mg} / \mathrm{kg})$ and xylazine (10 mg/kg) (Isackson et al., 1991; Gall and Lauterborn, 1992). The bipolar stimulating electrode (twisted Teflon-insulated $70 \mu \mathrm{m}$ platinum-iridium wire) was placed in the angular bundle (stereotaxic coordinates, $4.5 \mathrm{~mm}$ lateral and $7.8 \mathrm{~mm}$ posterior to bregma) at a depth giving the maximal population spike in hippocampus. The recording electrode $(0.025 \mathrm{~cm}$ parylene-insulated tungsten wire $)$ was placed in the ipsilateral dentate gyrus ( $2.5 \mathrm{~mm}$ lateral and $3.8 \mathrm{~mm}$ posterior to bregma), and the perforant path was stimulated $(10 \mathrm{~Hz}, 500 \mu \mathrm{A})$ for $7-10 \mathrm{sec}$, long enough to induce a PD. With PD onset, stimulation was terminated and the duration of the afterdischarge recorded. Rats were then returned to their home cage and were generally alert by $30 \mathrm{~min}$ after stimulation.

\section{In vitro experiments}

Cultured hippocampal slices were prepared from Sprague Dawley rat pups (11-12 d postnatal) (Charles River, Wilmington, MA) $(n=5)$ as described previously (Stoppini et al., 1991; Rivera et al., 1994). Slices were explanted onto Millicel-CM biomembranes (Millipore, St. Louis, MO) in a culture cluster plate (Corning, Cambridge, MA) containing sterile medium consisting of (in $\mathrm{mM}$ ): 30 dextrose, 30 HEPES, 5 $\mathrm{Na}_{2} \mathrm{HCO}_{3}, 3$ glutamine, 0.5 ascorbic acid, $2 \mathrm{CaCl}_{2}, 2.5 \mathrm{MgSO}_{4}$; minimum essential medium (Sigma); $1 \mathrm{mg} / \mathrm{l}$ insulin (Sigma); and $20 \%$ horse serum (Sigma), pH 7.2. For each animal, slices from both hippocampi were explanted onto four biomembranes (five to six slices per membrane group). The tissue was maintained for $18-21 \mathrm{~d}$ in a humidified incubator at $37^{\circ} \mathrm{C}$ in $5 \% \mathrm{CO}_{2}$; medium was changed three times a week. Twentyfour hours before drug experiments, slices were transferred to serum-free medium.
A single experiment included four groups of slices from each animal. Group 1 served as untreated controls. Group 2 was treated with $20 \mu \mathrm{M}$ kainic acid for $15 \mathrm{~min}$, washed with serum-free medium for $5 \mathrm{~min}$, and then maintained in serum-free medium. Group 3 received $35 \mu \mathrm{M}$ cycloheximide (CHX) (Sigma) for $30 \mathrm{~min}$, followed by kainic acid $(20 \mu \mathrm{M})$ in the presence of $\mathrm{CHX}$ for $15 \mathrm{~min}$, and was then washed $(5 \mathrm{~min})$ and maintained in serum-free medium (like group 2). Group 4 was incubated in CHX $(35 \mu \mathrm{M})$ alone for $30 \mathrm{~min}$ and then washed $(5 \mathrm{~min})$ and maintained in serum-free medium. The washing medium used for groups 3 and 4 contained $35 \mu \mathrm{M}$ CHX. Treatment was terminated $2 \mathrm{hr}$ after first treatment with kainic acid (or control medium) by fixation with $4 \%$ paraformaldehyde in PB. After overnight fixation, the slices were cryoprotected with $20 \%$ sucrose in $4 \%$ paraformaldehyde and then sectioned parallel to their broad surface at a thickness of $20 \mu \mathrm{m}$ using a freezing microtome. Sections from all four groups were mounted together onto Vectabond-treated slides (Vector Labs, Burlingame, CA), air dried, and stored at $-50^{\circ} \mathrm{C}$ until processed for in situ hybridization, as described below.

\section{$\left[{ }^{3} H\right]$ valine incorporation}

Incorporation of $\left[{ }^{3} \mathrm{H}\right]$ valine (DuPont NEN, Boston, MA) into protein was used as an index of the efficiency of protein synthesis inhibition for cultured hippocampal slices. All cultures from two rats were incubated with a D-valine (Sigma) serum-free medium for $1 \mathrm{hr}$. Some cultures were then incubated for $30 \mathrm{~min}$ with $\mathrm{CHX}$ at 10,35 , or $70 \mu \mathrm{M}$. After incubations, $3 \mu \mathrm{Ci} / \mathrm{ml}\left[{ }^{3} \mathrm{H}\right] \mathrm{L}$-valine $(3 \mu \mathrm{l} / \mathrm{ml})$ was added to all cultures for $1-3 \mathrm{hr}$; the incorporation was stopped by washing in serum-free medium containing $0.1 \mathrm{mg} / \mathrm{ml}$ of nonradioactive L-valine (Sigma). Cultures were then homogenized in $10 \% \mathrm{TCA}$ at $4^{\circ} \mathrm{C}$ and centrifuged for $5 \mathrm{~min}$ at $12,000 \mathrm{rpm}$. Pellets were washed in 5\% TCA and digested in $1 \mathrm{M} \mathrm{NaOH}$ $\left(37^{\circ} \mathrm{C}\right.$, overnight). For each sample, one aliquot was used for liquid scintillation autography, and another was measured for protein content (Bradford, 1976).

\section{$c R N A$ probe preparation}

All cRNA probes were transcribed in the presence of ${ }^{35} \mathrm{~S}$-labeled UTP (DuPont NEN). The rat NGF antisense transcripts were generated from the $P v u$ II-digested genomic clone pBSNGF using T3 RNA polymerase (Stratagene, La Jolla, CA); the probe is 970 bases long with a span complementary to 750 bases of the coding region of rat NGF mRNA (Whittemore et al., 1988). The cRNA to BDNF exon V (referred to here as the pan-BDNF cRNA) was generated from $P v u$ II-digested recombinant plasmid pR1112-8 (Isackson et al., 1991) using T3 RNA polymerase yielding a 540-base-length probe with 384 bases complementary to the coding region of BDNF exon V-containing mRNA (Timmusk et al., 1993). Exon V contains the coding region for 10 amino acids of the $\mathrm{N}$-terminal precursor region and the 119 amino acid mature BDNF protein. For BDNF exon I-IV probes, PCR fragments were obtain by amplification of mouse genomic DNA with 20 base oligonucleotides corresponding to rat sequences from the genomic fragments of Timmusk et al. (1993). PCR-amplified fragments were gel-purified, blunt-ended with T4 DNA polymerase, and ligated to HincII-digested, phosphatasetreated pBS (Stratagene). The identity of isolated recombinant plasmids was confirmed by DNA sequence analysis (Hayes et al., 1995). The exon I-specific clone pVE1 contains a $378 \mathrm{bp}$ cDNA fragment corresponding to bases 787-1165 (genomic fragment A); pVE2 contains a 468 bp fragment corresponding to bases 1761-2229 of exon II (genomic fragment A); pVE3 contains a $391 \mathrm{bp}$ fragment corresponding to bases $636-1027$ of exon III (genomic fragment B); and pVE4 contains a 350 bp fragment corresponding to bases $1730-2080$ of exon IV (genomic fragment B). Antisense probes were transcribed from PstI-digested pVE1, PvuIIdigested pVE2, and HindIII-digested pVE3, using T7 RNA polymerase

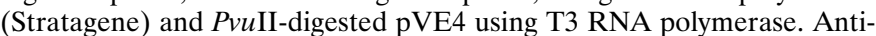
sense c-fos cRNA, complementary to bases 583-1250 of rat c-fos mRNA (Curran et al., 1987), was transcribed from PstI-digested recombinant clone $\mathrm{pBS} / \mathrm{rfos}$ using T7 RNA polymerase.

\section{In situ hybridization}

In situ hybridization procedures for slide-mounted and free-floating tissue were as described elsewhere (Lauterborn et al., 1994; Gall et al., 1995), with hybridization incubation of 20-24 hr (exons I-IV) or 24-45 hr (pan-BDNF, NGF, and c-fos) at $60^{\circ} \mathrm{C}$ and the ${ }^{35} \mathrm{~S}$-labeled cRNA probe at a concentration of $1 \times 10^{6} \mathrm{cpm} / 100 \mu \mathrm{l}$. After hybridization, the tissue was rinsed in $4 \times$ saline sodium citrate $($ SSC) buffer $(1 \times$ SSC $=0.15 \mathrm{M}$ $\mathrm{NaCl} / 0.015 \mathrm{~m}$ NaCitrate), $\mathrm{pH} 7.0$, treated with $20 \mu \mathrm{g} / \mathrm{ml}$ ribonuclease A 
Figure 1. One afterdischarge increases BDNF and c-fos mRNAs in the presence of anisomycin. Dark-field photomicrographs showing the autoradiographic localization of pan-BDNF cRNA $(A-C)$ and c-fos cRNA $(D-F)$ in situ hybridization in sections through hippocampus and cortex of a control rat $(A, D)$ and experimental rats treated with a PD alone $(B, E)$ or with a PD in the presence of anisomycin $(C, F)$. For BDNF cRNA, the density of labeling in stratum granulosum (sg) appears similarly increased in the PD $(B)$ and $\mathrm{PD}$-anisomycin $(C)$ rats in comparison with the paired control $(A)$. For c-fos cRNA, the $\mathrm{PD}$ alone $(E)$ clearly increased labeling in both neocortex and neuronal lamina of hippocampus, whereas the PD + anisomycin $(F)$ increased hybridization in these areas as well as in the hippocampal molecular layers (placement indicated by asterisk in $D$ ). Scale bar, $1 \mathrm{~mm}$.
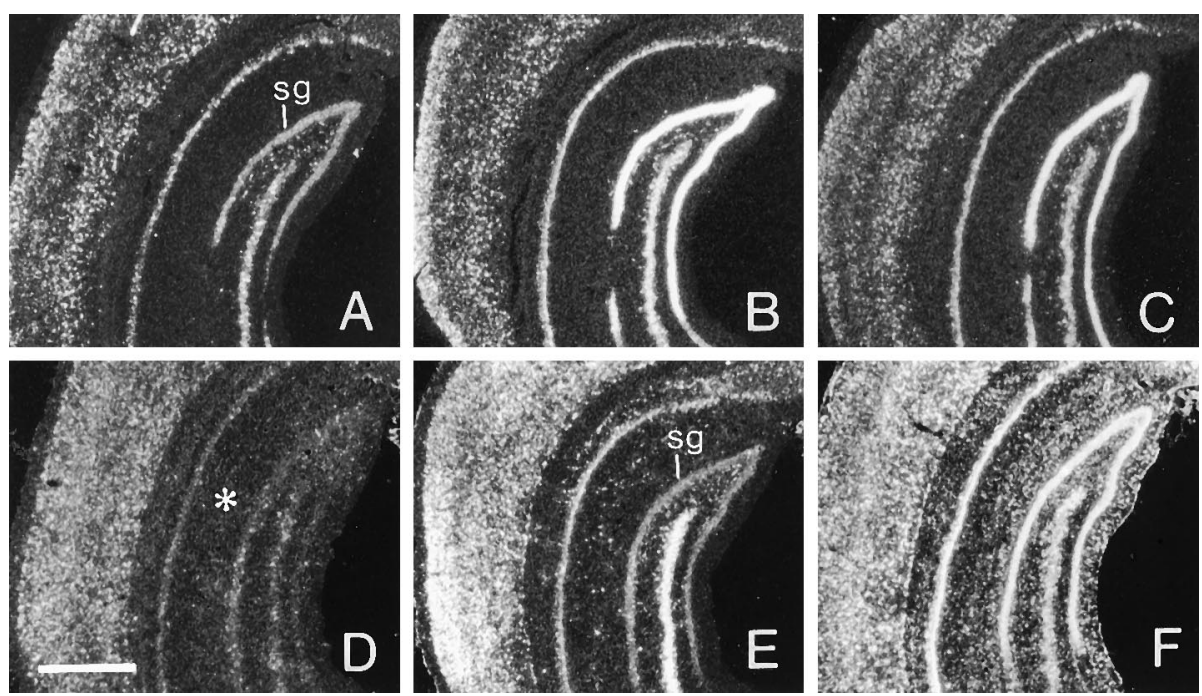

(Sigma) for $30 \mathrm{~min}$ at $45^{\circ} \mathrm{C}$, and washed through descending concentrations of SSC to a final wash in $0.1 \times \mathrm{SSC}$ at $60^{\circ} \mathrm{C}$. Free-floating sections were mounted onto gelatin-coated glass slides, and all tissue was exposed to Amersham $\beta$-max film (Amersham, Arlington Heights, IL) for 2-4 d. Slides were defatted through alcohol and chloroform and processed for emulsion autoradiography using Kodak NTB2 emulsion $\left(1: 1\right.$ with $\left.\mathrm{H}_{2} \mathrm{O}\right)$ (Eastman Kodak, Rochester, NY) with exposure at $4^{\circ} \mathrm{C}$ for 2-4 weeks. After emulsion development, the tissue was counterstained with cresyl violet and coverslipped with Permount.

Hybridization densities were measured from film autoradiograms and calibrated relative to film images of ${ }^{14} \mathrm{C}$-labeled brain paste standards (for details, see Gall et al., 1994) using the Microcomputer Imaging Device (Imaging Research, St. Catherines, Ontario). The standards were rated by counts per minute per $25 \mu \mathrm{g}$ protein, as determined by Bradford protein assay (Bradford, 1976); these same units of measure were applied to tissue hybridization densities reported here. For in vivo experiments, fields within the midseptotemporal hippocampus, contralateral to electrode placement, were analyzed. For each rat, the mean labeling density was calculated using multiple samples from at least five tissue sections. Although some data are presented in graphical form as percentage of control or maximal PD values, statistical significance was determined from uncorrected individual animal values in all cases. The significance of the effects of treatment was evaluated, in most instances, using the one-way ANOVA followed by the Student-Newman-Keuls post hoc test for paired comparisons. For the analysis of PD effects on NGF mRNA levels in the first set of rats, standard post hoc tests could not be applied because of significant differences in the SDs among groups. For this data set, significance was evaluated by ANOVA followed by the two-tailed Welch's $t$ test, which can accommodate groups with unequal SDs (Motulsky, 1995). All differences considered to be significant had $p$ values of $<0.05$ and, unless otherwise stated, $p$ values indicated within the text reflect the comparison with control values.

\section{RESULTS}

\section{Phase I: pan-BDNF (exon V) versus NGF mRNAs}

Effects of protein synthesis inhibition on BDNF $m R N A$ induction in vivo

To determine whether protein synthesis plays a critical role in activity-dependent changes in BDNF expression, the first set of experiments used the single, stimulated PD paradigm. Adult male rats were divided into four groups receiving (1) a single PD without any additional treatment, (2) anisomycin injection $30 \mathrm{~min}$ before and $30 \mathrm{~min}$ after a single $\mathrm{PD},(3)$ two anisomycin injections $1 \mathrm{hr}$ apart, and (4) two saline injections $1 \mathrm{hr}$ apart. Group 4 rats were considered saline controls. Rats received PD stimulation while under ketamine-xylazine anesthesia and were killed $2 \mathrm{hr}$ later; animals receiving injections alone were killed $1.5 \mathrm{hr}$ after the last injection. The $2 \mathrm{hr}$ survival interval was chosen, because
BDNF mRNA was maximally increased at $2 \mathrm{hr}$ post-PD in our own previous studies (Gall and Lauterborn, 1992) and in others (Ernfors et al., 1991). For all PD animals, the recorded afterdischarge ranged from 20 to $30 \mathrm{sec}$ in duration.

Tissue sections were processed for in situ hybridization with pan-BDNF cRNA (Isackson et al., 1991), which hybridizes to BDNF exon $\mathrm{V}$-containing mRNA and labels all BDNF transcripts (Timmusk et al., 1993). In control hippocampus, the pan-BDNF cRNA labels both the granule cell and pyramidal cell layers (Ernfors et al., 1990; Isackson et al., 1991). Stimulation of the entorhinal cortical efferents would be expected to provide strong monosynaptic excitatory drive to the dentate gyrus granule cells and, largely through projections of the granule cells, weaker excitatory afferent drive to CA3 stratum pyramidale. Hybridization was quantified for both of these fields, as well as for CA1 stratum pyramidale. As seen in the Figure 1 photomicrographs and the bar graphs in Figure 2, in stratum granulosum, hybridization of the pan-BDNF cRNA was markedly increased above control levels by a single PD. Labeling was increased to a slightly lesser extent in the PD-anisomycin group, although values were not significantly different from the group receiving a PD alone. In rats treated with anisomycin alone, labeling densities were not significantly different from measures of saline control rats (Fig. 2).

Similar results were obtained for the effects of PD stimulation on region CA3 stratum pyramidale. For both PD and PD-anisomycin treatment groups, hybridization was modestly greater than in rats treated with saline alone $(p<0.01)$; anisomycin treatment alone had no significant effect on labeling densities (Fig. 2). In region CA1, pan-BDNF cRNA labeling did not differ from control values for any experimental group (data not shown).

\section{Comparison with NGF}

In control hippocampus, NGF mRNA is expressed by the dentate granule cells and by GABAergic neurons scattered across all hippocampal lamina (Lauterborn et al., 1993). After a single PD, NGF cRNA hybridization was greatly increased in stratum granulosum as reported previously (Ernfors et al., 1991; Gall and Lauterborn, 1992). As shown in Figure 2, anisomycin attenuated the PD-induced increase in NGF cRNA hybridization in this cell layer, although the difference between the PD and PD-anisomycin groups was not statistically significant ( $p=0.27$, Welch's $t$ test). Anisomycin applied alone significantly increased labeling 


\section{Str. Granulosum}

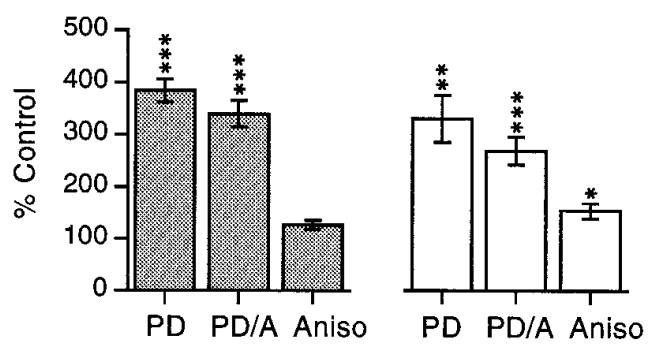

CA3 Str. Pyramidale

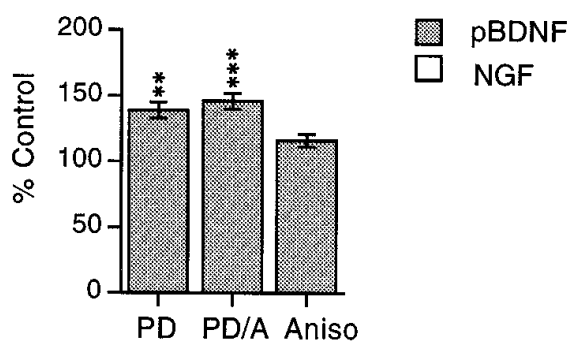

Figure 2. Quantification of PD-induced increases in BDNF and NGF mRNAs with and without protein synthesis inhibition. Bar graphs showing the densities of pan-BDNF cRNA $(p B D N F)$ and NGF cRNA $(N G F)$ labeling of stratum granulosum (top graphs) and CA3 stratum pyramidale (bottom graph) in rats receiving a PD alone $(P D)$, a PD in the presence of anisomycin $(P D / A)$, or anisomycin alone (Aniso). Density measures represent group means ( $\pm \mathrm{SE} ; n \geq 5$ per group) and are expressed as a percent of labeling density measures from paired control rats. For stratum granulosum, BDNF cRNA hybridization was increased to comparable levels in the PD and PD/A groups. For NGF cRNA, anisomycin increased hybridization when applied alone and slightly attenuated but did not prevent the increase in labeling elicited by a single PD. Significance levels calculated from raw data by ANOVA followed by Student-NewmanKeuls post hoc test for BDNF and by Welch's $t$ test for NGF; * $p<0.05$, ${ }^{* *} p<0.01,{ }^{* * *} p<0.001$ for comparison with control group.

above saline control values ( $p=0.013$, Welch's $t$ test). Thus, NGF cRNA hybridization measured in the PD/anisomycin group would be expected to reflect the effects of the PD as well as the effects of anisomycin.

\section{Elevated c-fos expression after anisomycin}

The anisomycin dose used here has been demonstrated to reduce protein synthesis in brain by $90 \%$ over the test interval (Bennett et al., 1972; Flood et al., 1973). To check the efficacy of in vivo anisomycin treatment in the present material, a third set of tissue sections was processed for the in situ hybridization localization of $c$-fos mRNA. Previous studies have demonstrated that c-fos mRNA is superinduced in the presence of protein synthesis inhibitors (Mocchetti et al., 1989). As seen in the Figure 1 photomicrographs, and corroborated by quantification of hybridization densities (data not shown), a single PD markedly increased $c$-fos cRNA labeling in both the granule and pyramidal cell layers of hippocampus. Anisomycin alone induced a more modest increase in c-fos mRNA within these cell layers as well as within CA1 stratum lacunosum moleculare $(p<0.05)$. In PD-anisomycin rats, $c$-fos mRNA levels were greater than in rats receiving a PD alone, not only in stratum granulosum but also within the pyramidal and molecular layers of hippocampus and within neocortex. Thus, labeling was elevated for several neuron types as well as for glial cells that predominate in the hippocampal molecular layers. These results indicate that the present anisomycin treatment did not attenuate the activity-induction of this IEG and superinduced c-fos mRNA across all major hippocampal cell types.

\section{In vitro experiments}

The effect of protein synthesis inhibition on neurotrophin expression was investigated further using the cultured hippocampal slice preparation (Stoppini et al., 1991; Rivera et al., 1994), in which protein synthesis inhibitors could be directly applied. Hippocampal slices from 11- to 12-d-old rats were explanted to culture for 2 weeks before treatment with kainic acid in the presence and absence of the protein synthesis inhibitor CHX. To determine the efficiency of CHX treatment, three separate concentrations (10, 35 , and $70 \mu \mathrm{M}$ ) of the inhibitor were first tested for effects on amino acid incorporation. Evaluation of $\left[{ }^{3} \mathrm{H}\right]$ valine incorporation showed that 10,35 , and $70 \mu \mathrm{M} \mathrm{CHX}$ inhibited protein synthesis by 93.4, 96.9, and 97.4\%, respectively, within $1 \mathrm{hr}$ after the addition of the drug. The $35 \mu \mathrm{M}$ concentration was used for all in vitro neurotrophin experiments, because at this concentration, there was near-complete blockade of protein synthesis, and Nisslstained sections from treated slices did not show any overt morphological signs of neurotoxicity (data not shown).

To induce increases in neurotrophin mRNA expression, cultures were treated for $15 \mathrm{~min}$ with $20 \mu \mathrm{M}$ kainic acid; mRNA levels were assessed by densitometric analysis of in situ hybridization. As shown in Figure $3 A$, the distribution of pan-BDNF cRNA hybridization in the untreated explant is similar to the labeling pattern in sections from control rat brain with labeling of the granule and pyramidal cell layers and scattered cells in the hilus. In explants treated with kainic acid alone or in the presence of CHX (Fig. 3B), hybridization was markedly increased in the granule cell layer. Labeling was not consistently increased in stratum pyramidale at this survival interval. $\mathrm{CHX}$ attenuated the effect of kainic acid on BDNF mRNA content. As shown in Figure 4, in stratum granulosum, pan-BDNF cRNA labeling was significantly greater in kainic acid-treated as compared with control slices $(p<0.001)$. In tissue treated with $35 \mu \mathrm{M}$ CHX followed by kainic acid, labeling was lower than in slices treated with kainic acid alone $(p<0.01)$ and was not significantly different from labeling in slices treated with $\mathrm{CHX}$ alone. CHX applied alone had no significant effect on pan-BDNF cRNA labeling in any subfield.

In explants treated with kainic acid and with kainic acid + CHX, NGF cRNA labeling of stratum granulosum was significantly increased above control values $(p<0.001$ and $p<0.05$, respectively). However, with combined kainic acid + CHX treatment, granule cell labeling was lower and significantly different from that in slices treated with kainic acid alone $(p<0.01)$ and was not significantly different than measures of slices treated with CHX alone.

\section{Phase II: BDNF exons I-IV}

\section{Effects of protein synthesis inhibition on BDNF transcripts in vivo}

To determine whether protein synthesis inhibition had selective effects on activity-dependent increases in the expression of transcripts containing BDNF exons I-IV, the in vivo stimulation experiments were repeated using a second set of rats and the same four treatment groups: control, PD alone, PD-anisomycin, and anisomycin alone. Tissue sections from all four groups were processed for in situ hybridization of BDNF exon I-V cRNAs and NGF cRNA. The pan-BDNF and NGF mRNAs were evaluated to compare the effectiveness of treatment between the first (phase I) and second (phase II) sets of rats. 

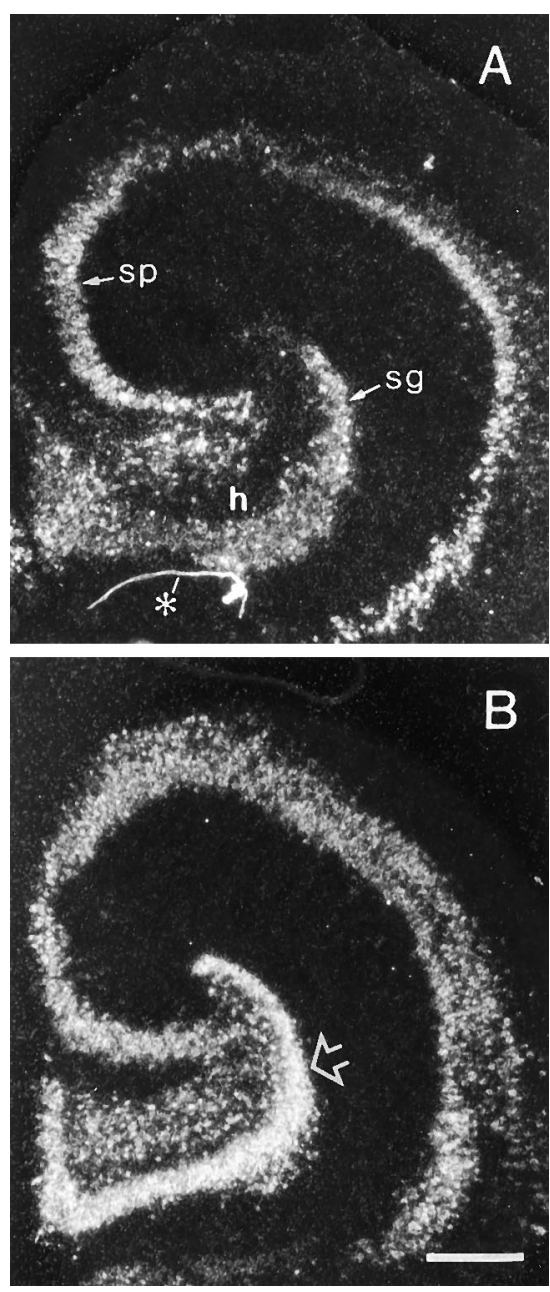

Figure 3. Kainic acid increases the BDNF mRNA content of hippocampal neurons in the presence of CHX. Dark-field photomicrographs showing the autoradiographic localization of pan-BDNF cRNA in situ hybridization in sections through control cultured hippocampus $(A)$ and cultured hippocampus treated with kainic acid in the presence of CHX (B). Open arrow indicates the zone of stratum granulosum measured for quantitative analysis presented in Figure 4. In comparison with the control explant $(A)$, labeling of stratum granulosum $(\mathrm{sg})$ is markedly greater in the slice treated with kainic acid $(B)$. In both cases, hybridization is limited to cells in the neuronal lamina and hilus $(h) . s p$, Stratum pyramidale; asterisk indicates artifact in $A$. Scale bar, $400 \mu \mathrm{m}$.

As shown in the Figure 5 photomicrographs and the quantification of labeling densities presented in Figure 6, a PD alone markedly increased hybridization to mRNAs containing exons I-IV in stratum granulosum. However, in rats receiving both a PD and anisomycin, there were clear differences in the effect of the afterdischarge among BDNF transcripts. As shown in Figures 5, $C$ and $F$, and $6 A$, anisomycin severely attenuated the PD-induced increase in exon I and II cRNA hybridization. Exon I cRNA labeling was $56 \%$ lower in the PD-anisomycin group as compared with the PD-alone group $(p<0.05)$. Similarly, exon II cRNA labeling was $55 \%$ lower in the PD-anisomycin group than in the PD-alone group $(p<0.001)$. For the exon I cRNA, labeling in $\mathrm{PD}-$ anisomycin rats was not significantly greater than in rats given anisomycin alone. For exon II cRNA, hybridization densities in $\mathrm{PD}-$ anisomycin rats were significantly greater than measures from both the anisomycin and saline control groups $(p<0.01$, both comparisons).

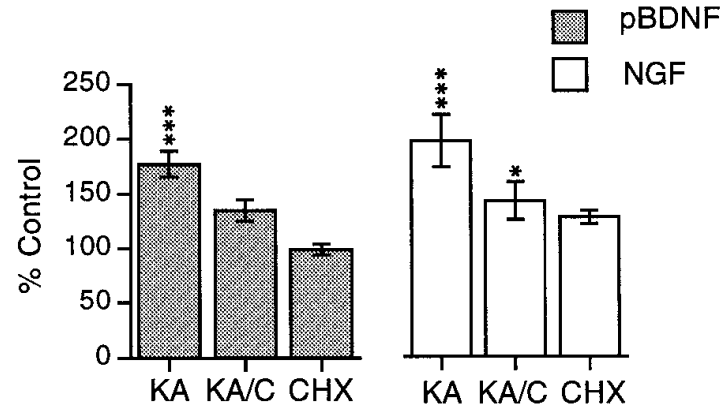

Figure 4. Quantification of kainic acid-induced increases in BDNF and NGF mRNA in hippocampal explants. Bar graphs showing measures of pan-BDNF cRNA ( $p B D N F)$ and NGF cRNA $(N G F)$ labeling in the stratum granulosum in sections through cultured hippocampus treated with kainic acid alone $(K A)$, kainic acid in the presence of $\mathrm{CHX}(K A / C)$, or CHX alone $(\mathrm{CHX})$. Measures from drug-treated tissue are expressed as a percent of values from paired control explants. The values plotted represent group means $\pm \mathrm{SE}$ for $n=7$ per group for pan-BDNF and $n=$ 4 per group for NGF. As determined from statistical analyses using raw measures, the effect of treatment was significant for both cRNAs $(p<$ 0.001 , ANOVA). In comparison with control (vehicle-treated) tissue, kainic acid increased mean hybridization densities when applied alone $\left({ }^{* *} p<0.001\right)$ or in the presence of CHX, although the latter was not statistically significant; labeling was significantly lower in the kainic acid/ CHX group as compared with the kainic acid-alone group $(p<0.01)$. Similarly, for the NGF cRNA, kainic acid applied alone or in the presence of CHX increased granule cell labeling $\left({ }^{* * *} p<0.001\right.$ and $* p<0.05$, respectively, for comparison with control tissue), although with the combined treatment $(K A / C)$, measures were lower than with kainic acid applied alone $(K A ; p<0.01)$.

In contrast to the effects of anisomycin on BDNF transcripts containing exons I and II, for transcripts containing exons III and IV, labeling in the PD-anisomycin group was not significantly different from labeling in the PD-alone group (Figs. 5, 6B). For exon III and IV cRNAs, labeling in both the PD and PDanisomycin groups was greatly elevated above measures from the anisomycin-alone and saline control groups. For exon III cRNA, these differences were statistically significant $(p<0.01$ for both comparisons). Although mean exon IV cRNA hybridization densities were altered by stimulation ( $p=0.045$, ANOVA) and greater in $\mathrm{PD}$ and $\mathrm{PD}$-anisomycin rats as compared with anisomycin-alone and saline controls, with the variability obtained with this probe, the group values were not significantly different in post hoc comparisons. Finally, the effects of PD, PD-anisomycin, and anisomycin alone on pan-BDNF cRNA and NGF cRNA hybridization labeling were comparable in the first and second sets of rats (i.e., phase I and phase II) (Fig. 6C).

\section{Time course of BDNF exon I-IV induction after afterdischarge stimulation}

The observation that anisomycin attenuates PD-induced increases in mRNAs containing exons I and II but does not affect increases in mRNAs containing exons III and IV indicates that the latter transcripts are regulated as IEGs in this paradigm. To determine whether mRNAs containing exons III and IV are particularly rapidly induced with $\mathrm{PD}$ stimulation, additional rats receiving a single PD were used to determine the time course of increases in the different BDNF transcripts. Rats were killed from 15 min to 2 hr after one PD. Transcripts containing BDNF exons III and IV were indeed most rapidly induced after PD stimulation (Fig. 7). Exon IV-containing mRNA was significantly increased over control levels by $15 \min (p<0.05)$ and continued to rise to reach maximal densities of fourfold above control values at $1 \mathrm{hr}(p<$ 

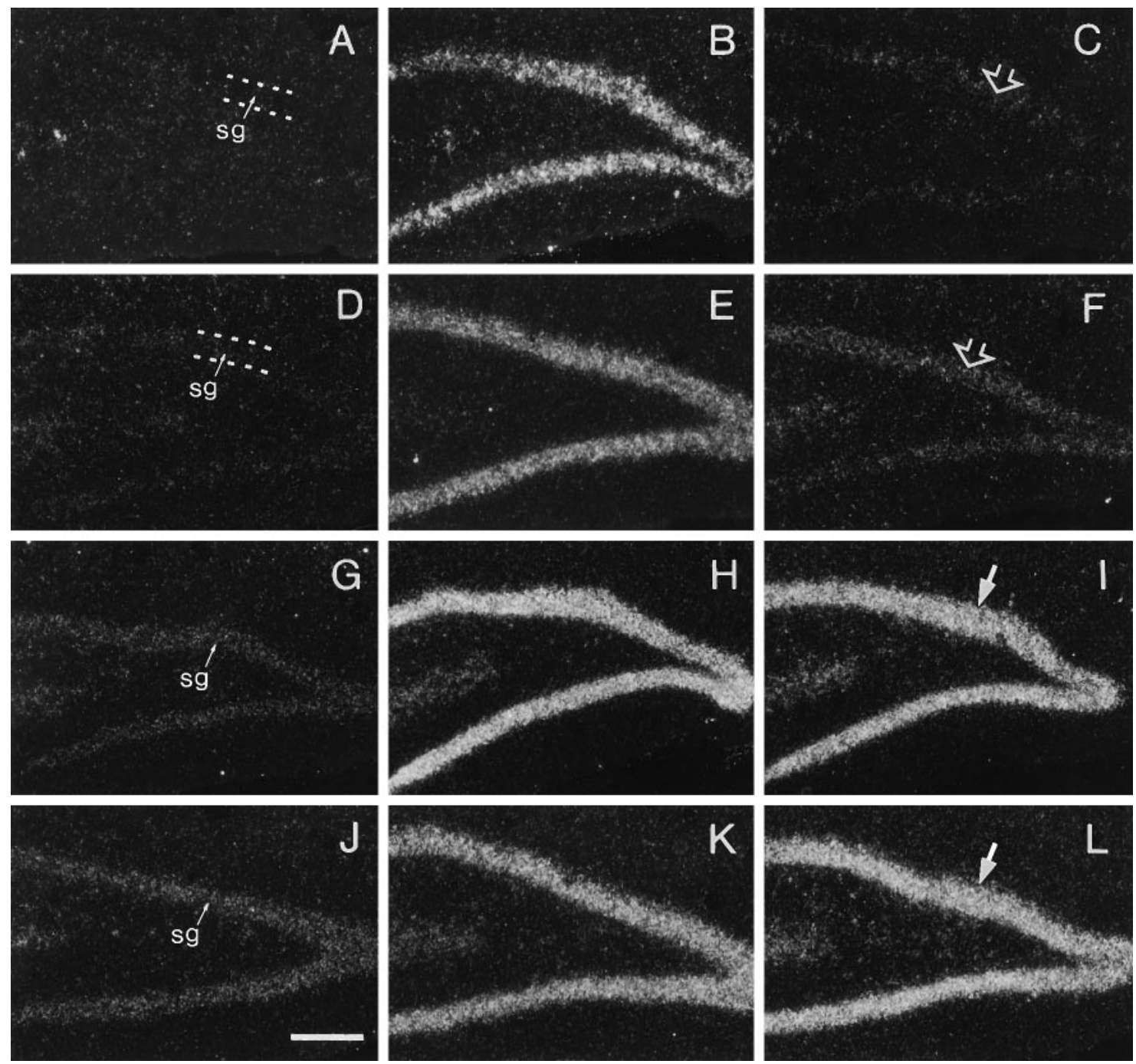

Figure 5. Anisomycin blocks PD-induced increases in the expression of BDNF transcripts containing exons I and II but not transcripts containing exons III and IV. Dark-field photomicrographs showing labeling of stratum granulosum ( $s g$ ) with cRNAs for BDNF exon I- $(A-C)$, exon II- $(D-F)$, exon III$(G-I)$, and exon IV- $(J-L)$ containing transcripts in sections through hippocampus of a control rat $(A, D, G, J)$, a rat killed $2 \mathrm{hr}$ after a PD applied alone $(B, E, H, K)$, and a rat killed $2 \mathrm{hr}$ after a PD applied in the presence of anisomycin $(C, F, I, L)$. Note that a PD applied alone increased hybridization of all four transcript cRNAs in stratum granulosum; anisomycin cotreatment virtually eliminated the PD-induced increase in exon I cRNA $(C)$ and exon II cRNA $(F)$ labeling but did not appear to attenuate the PD-induced increase in exon III $(I)$ or exon IV $(L)$ cRNA labeling. Scale bar, $200 \mu \mathrm{m}$.

0.001). Hybridization declined through the next hour but remained significantly greater than control values $(p<0.05)$. Exon III cRNA labeling also increased rapidly through the first $30 \mathrm{~min}$, although with the numbers of animals used and variability obtained, increases were not statistically significant until $1 \mathrm{hr}$ after stimulation $(p<0.01)$. Exon III-containing mRNA levels remained well elevated through $2 \mathrm{hr}$. Increases in exon I- and II-containing transcripts were relatively smaller and slower to develop (Fig. 7). Hybridization of exon II cRNA was modestly increased by $30 \mathrm{~min}$ post-PD and reached maximal levels at $1 \mathrm{hr}$ post-PD ( $p<0.001$ vs control). Exon I-containing mRNA levels rose slowly and only became significantly elevated above control values at $2 \mathrm{hr}$ after stimulation $(p<0.01)$.

\section{DISCUSSION}

The present studies were undertaken to determine whether the activity-dependent changes in neuronal BDNF mRNA expression could occur in the presence of protein synthesis inhibition as expected if this were an IEG response. The analysis of pan-BDNF
cRNA hybridization in vivo demonstrated that PD-induced increases in BDNF mRNA in hippocampal stratum granulosum and CA3 stratum pyramidale were attenuated but not significantly blocked by anisomycin. In the cultured hippocampal slice, kainic acid-induced increases in pan-BDNF cRNA labeling were significantly reduced in the presence of $\mathrm{CHX}$, although hybridization was still higher than in control tissue. These data suggest that although neuronal activity can elicit increases in BDNF mRNA expression in the presence of protein synthesis inhibition, some component of the full response is blocked by drug treatment. Using exon-specific cRNA probes, which distinguish between the multiple BDNF transcripts, to resolve the basis of these partial effects revealed that mRNAs containing the four $5^{\prime}$ exons were differentially regulated by activity in the presence of protein synthesis inhibitors. PD-induced increases in transcripts containing exons I and II were markedly attenuated by anisomycin, whereas PD-induced increases in transcripts containing exons III and IV were not affected by protein synthesis blockade. These 

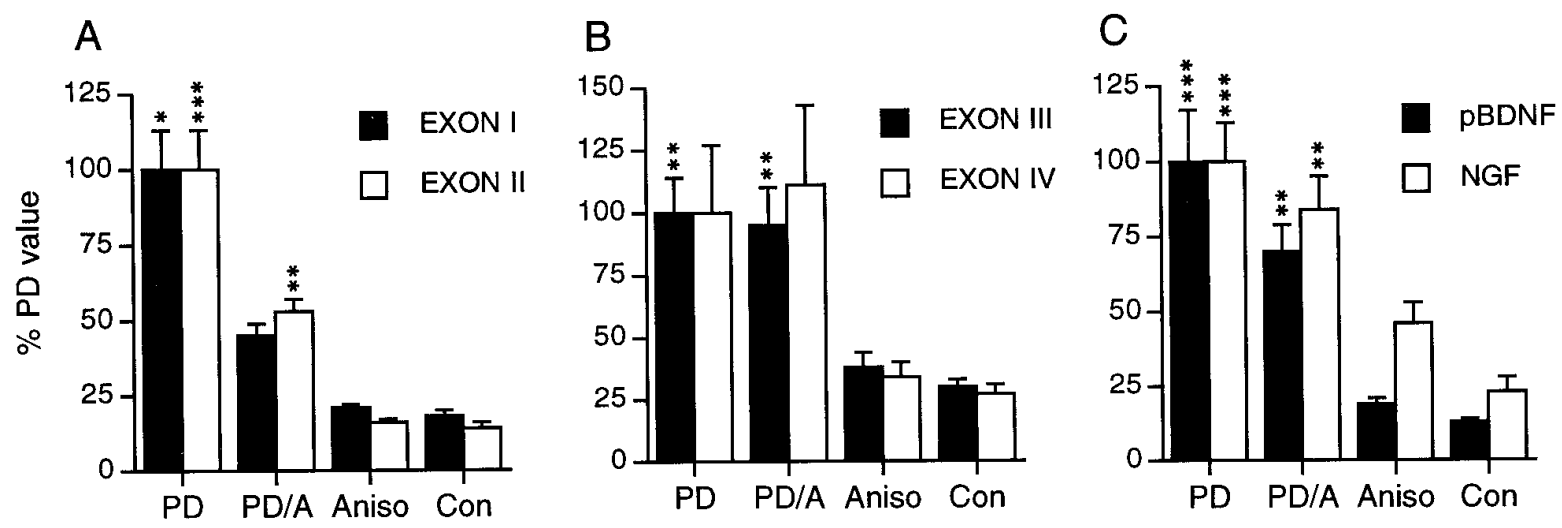

Figure 6. Quantification of afterdischarge-induced changes in the expression of the different BDNF transcripts and of NGF with and without anisomycin treatment. Bar graphs show measures of BDNF and NGF cRNA in situ hybridization labeling of stratum granulosum in tissue sections from unstimulated control rats (Con) and rats receiving a PD alone (PD), a PD applied in the presence of anisomycin (PD/A), and anisomycin alone (Aniso) (phase II set). Values represent group means \pm SE for $n \geq 7$ per group and are expressed as a percent of the maximal labeling density measure, which for each cRNA, was obtained in the PD-alone group. Statistical analyses conducted using raw density measures. Treatments induced significant changes in hybridization density for each cRNA ( $p<0.0002$ for pBDNF, NGF, exon II, and exon III cRNAs; $p<0.02$ for exon I; and $p<0.05$ for exon IV; ANOVA main effect of treatment). Asterisks indicate significant differences from control values $\left({ }^{* * *} p<0.001 ;{ }^{* *} p<0.01 ;{ }^{*} p<0.05\right.$; Student-Newman-Keuls post hoc test). See text for significance values of additional paired comparisons.

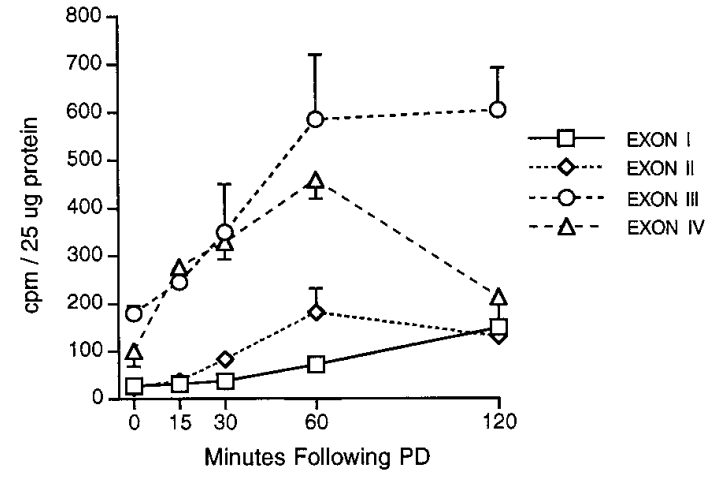

Figure 7. BDNF transcripts are increased by different time courses after one afterdischarge. Line graph showing the densities of in situ hybridization labeling of stratum granulosum with cRNAs for BDNF transcripts containing exons $\mathrm{I}-\mathrm{IV}$ in rats killed at a range of time points after the stimulation of a single PD. Each point represents the mean $\pm \operatorname{SE}$ from $n \geq$ 3 per group. See Results for statistical analyses.

data demonstrate that different cellular mechanisms are engaged in the activity-dependent regulation of BDNF mRNAs containing exons I and II as compared with those containing exons III and IV and, in particular, show that transcripts containing exons III and IV can be regulated as IEGs. These results could reflect the independent induction of the distinct promoters $5^{\prime}$ to exons III and IV, but the possibility that the exon IV cRNA labeled unspliced transcripts resulting from promotor III activation cannot be excluded.

Hughes et al. (1993) found that pretreatment with CHX did not block the increase in total BDNF (exon V) mRNA content induced by the damage of an intrahippocampal saline injection. This is consistent with the conclusion that damage induces BDNF as an IEG and, together with the present results, that BDNF is regulated as an IEG under a variety of conditions. The specific BDNF transcripts induced by local damage have not been examined. However, the finding that damage-induced increases in BDNF expression are not attenuated by protein synthesis inhibition suggests that in contrast to the effects of seizures, damage may induce only those transcripts that are regulated as IEGs.
Interestingly, much like effects on pan-BDNF mRNA, we found that PD- and kainic acid-induced increases in NGF mRNA content were modestly attenuated but not blocked by protein synthesis inhibition. Appreciation of the magnitude of changes in NGF expression induced specifically by activity in these preparations is confounded by the fact that $\mathrm{CHX}$ or anisomycin treatment alone increased NGF mRNA levels. Nevertheless, these results suggest that activity-induced increases in NGF mRNA content include components that are, and are not, dependent on protein synthesis. Increases in NGF mRNA induced in cultured fibroblasts by phorbol ester or serum (D’Mello and Heinrich, 1990; Wion et al., 1990) and in cultured astroglia by phorbol ester (Omae et al., 1994), cytokines (Vigé et al., 1991), or isoproterenol (Mocchetti et al., 1989) are blocked or significantly attenuated by CHX. This is consistent with the proposal that NGF expression is regulated to large extent through the activities of transcriptional regulatory factors at an AP-1 site within the first intron of the NGF gene (Mocchetti et al., 1989; Hengerer et al., 1990; D'Mello and Heinrich, 1991; Cowie et al., 1994). However, it is probable that there are multiple, differentially regulated NGF transcripts in rat brain. Like both BDNF (Timmusk et al., 1993) and neurotrophin-3 (Leingärtner and Lindholm, 1994), the NGF gene has multiple exons $5^{\prime}$ to the coding region (Selby et al., 1987). In mouse, alternative splicing and independent initiation of transcription from two promoters gives rise to four different NGF transcripts (Selby et al., 1987). It will be of interest if multiple NGF transcripts are present and differentially regulated by activity in the presence of protein synthesis inhibition in rat brain.

In contrast to some of the better characterized IEG mRNAs (e.g., c-fos, c-jun, zif-268, and tissue plasminogen activator) (Edwards and Mahadevan, 1992; Hughes et al., 1993; Qian et al., 1993), BDNF mRNA was not induced by CHX treatment alone or superinduced by stimulation in the presence of protein synthesis inhibition. For c-fos, CHX-induced increases in mRNA content have been attributed to several processes including an increase in mRNA half-life possibly arising from depletion of labile degradative enzymes, interference with negative end-product inhibition of gene transcription (Sassone-Corsi et al., 1988), and a direct activation of transcription (Edwards and Mahadevan, 1992). The lack 
of BDNF superinduction suggests that highly labile transcriptional regulatory factors or degradative enzymes do not contribute significantly to BDNF mRNA levels in the basal state or to the rate of BDNF mRNA decay after stimulation. In contrast, the NGF mRNA content of hippocampal neurons was increased by both anisomycin and $\mathrm{CHX}$; this is, to our knowledge, the first observation of such induction in forebrain neurons. $\mathrm{CHX}$ increases NGF mRNA levels in cultured astroglia (Mocchetti et al., 1989; Vigé et al., 1991) but not in transformed fibroblasts (D'Mello and Heinrich, 1990; Wion et al., 1990). The increase in astroglia has been suggested to be attributable to increased NGF mRNA half-life (Mocchetti et al., 1989; Vigé et al., 1991), but the possibility of direct drug effects on NGF transcription has not been examined.

The time courses of PD-induced changes in BDNF transcripts levels are consistent with there being fundamental differences in the mechanisms that regulate the expression of mRNAs containing exons I and II as compared with mRNAs containing exons III and IV and with the conclusion that the exon III- and IVcontaining mRNAs are regulated as IEGs. After one afterdischarge, mRNAs containing exons III and IV are well elevated by $15 \mathrm{~min}$ and attain maximal levels by $1 \mathrm{hr}$. In contrast, mRNAs containing exons I and II were only clearly elevated at $60 \mathrm{~min}$ and at maximal levels at $2 \mathrm{hr}$ after stimulation. These results are in agreement with Kokaia et al. (1994a), who reported that elevations in exon III-containing mRNA precede increases in exon I-containing mRNA and that mRNAs containing exons I-III were all markedly elevated $2 \mathrm{hr}$ after one afterdischarge. One interesting difference between the effects of a single afterdischarge and changes in BDNF mRNA content induced in recurrent seizure paradigms relates to the relative magnitude of increases in the different transcripts. With one afterdischarge, exon III/IVcontaining mRNAs are more greatly increased than exon I/IIcontaining mRNAs. In recurrent seizure paradigms, the reverse is true (Metsis et al., 1993; Timmusk et al., 1993; Kokaia et al., 1994a) (C. Gall and J. C. Lauterborn, unpublished observations). It has been reported that the increase in BDNF mRNA induced by a single afterdischarge is an "all-or-none" response and does not reflect the duration of the epileptiform burst (Bengzon et al., 1993). It is possible that the increase in exon III/IV-containing mRNAs, which predominates after one afterdischarge, is indeed an all-or-none response, whereas the increase in exon I/IIcontaining mRNA is graded and builds with recurrent bursts or longer periods of epileptiform activity to predominate after recurrent seizures.

The demonstration that select BDNF transcripts are regulated as IEGs suggests a molecular basis for regional differences in the levels of neuronal activity needed to activate BDNF-mediated forms of neuroplasticity. The simpler mechanistic requirements for inducing IEG as compared with non-IEG transcripts suggest the possibility that the IEG forms (i.e., exons III and IV) are induced with lower activation threshold. Although this idea has not been tested, it is consistent with the observation that among BDNF transcripts, exon III-containing mRNA is the most reliably increased across paradigms (e.g., seizure, hypoglycemia, ischemia) (Metsis et al., 1993; Timmusk et al., 1993; Kokaia et al., 1994a). By contrast, exon I-containing mRNA is induced to a far lesser extent by hypoglycemia, and exons I and II are reportedly not induced by ischemia (Kokaia et al., 1994a). Furthermore, there are regional differences in BDNF transcript expression. For example, glutamate receptor activation increases exon I-IV-containing mRNAs in the granule cells, most markedly increases exon III-containing
mRNA in CA1 stratum pyramidale, but predominantly increases exon I-containing mRNA in CA3 stratum pyramidale (Falkenberg et al., 1993; Metsis et al., 1993; Timmusk et al., 1993; Kokaia et al., 1994a). These differences in cellular expression profiles, considered with the possibility of different thresholds to induction across the BDNF promoters, suggest that neuronal populations expressing the IEG transcripts may be more likely to exhibit changes in BDNF synthesis in response to alterations in neuronal activity within the normal physiological range. Although this idea is highly speculative at present, it could be tested by determining whether for a neuronal population expressing all BDNF transcripts, the expression of BDNF mRNAs containing exons III and IV can be elicited with a lower activation threshold.

\section{REFERENCES}

Bengzon J, Soderstrom S, Kokaia Z, Kokaia M, Ernfors P, Persson H, Ebendal T, Lindvall O (1992) Widespread increase of nerve growth factor protein in the rat forebrain after kindling-induced seizures. Brain Res 587:338-342.

Bengzon J, Kokaia Z, Ernfors P, Kokaia M, Leanza G, Nilsson OG, Persson H, Lindvall O (1993) Regulation of neurotrophin and trkA, trkB and trkC tyrosine kinase receptor messenger RNA expression in kindling. Neuroscience 53:433-446.

Bennett EL, Orme A, Hebert M (1972) Cerebral protein synthesis inhibition and amnesia produced by scopolamine, cycloheximide, streptovitacin A, anisomycin, and emetine in rat. Fed Proc 31:838.

Bishop JF, Mueller GP, Mouradian MM (1994) Alternate 5' exons in the rat brain-derived neurotrophic factor gene: differential patterns of expression across brain regions. Mol Brain Res 26:225-232.

Bradford MM (1976) A rapid and sensitive method for the quantitation of microgram quantities of protein utilizing the principle of protein-dye binding. Anal Biochem 72:248-254.

Castrén E, Pitkänen M, Sirviö J, Parsadanian A, Lindholm D, Thoenen H, Riekkinen PJ (1993) The induction of LTP increases BDNF and NGF mRNA but decreases NT-3 mRNA in the dentate gyrus. NeuroReport 4:895-898.

Cowie A, Ivanco TL, Fahnestock M (1994) Mouse NGF promoter upstream sequences do not affect gene expression in mouse fibroblasts. Mol Brain Res 27:58-62.

Curran T, Gordon MB, Rubino KL, Sambucetti LC (1987) Isolation and characterization of the c-fos (rat) cDNA and analysis of posttranslational modification in vitro. Oncogene 2:79-84.

D'Mello S, Heinrich G (1990) Induction of nerve growth factor gene expression by $12-\mathrm{O}$-tetradecanoyl phorbol 13-acetate. J Neurochem 55:718-721.

D'Mello S, Heinrich G (1991) Nerve growth factor gene expression: involvement of a downstream AP-1 element in basal and modulated transcription. Mol Cell Neurosci 2:157-167.

Dragunow M, Beilharz E, Mason B, Lawlor P, Abraham W, Gluckman P (1993) Brain-derived neurotrophic factor expression after long-term potentiation. Neurosci Lett 160:232-236.

Edwards DR, Mahadevan LC (1992) Protein synthesis inhibitors differentially superinduce c-fos and c-jun by three distinct mechanisms: lack of evidence for labile repressors. EMBO J 11:2415-2424.

Ernfors P, Wetmore C, Olson L, Persson L (1990) Identification of cells in the rat brain and peripheral tissues expressing mRNA for members of the nerve growth factor family. Neuron 5:511-526.

Ernfors P, Bengzon J, Kokaia A, Persson H, Lindvall O (1991) Increased levels of messenger RNAs for neurotrophic factors in the brain during kindling epileptogenesis. Neuron 7:165-176.

Falkenberg T, Metsis M, Timmusk T, Lindefors N (1993) Entorhinal cortex regulation of multiple brain-derived neurotrophic factor promoters in the rat hippocampus. Neuroscience 57:891-896.

Flood JF, Rosenzweig MR, Bennett EL, Orme AE (1973) The influence of duration of protein synthesis inhibition on memory. Physiol Behav 10:555-562.

Gall C (1993) Seizure-induced changes in neurotrophin expression: implications for epilepsy. Exp Neurol 124:150-166.

Gall C, Lauterborn J (1992) The dentate gyrus: a model system for studies of neurotrophin regulation. In: The dentate gyrus and its role in seizures. Epilepsy Research Supplement (Ribak CE, Gall CM, Mody I, eds), pp 171-185. Amsterdam: Elsevier. 
Gall CM, Berschauer R, Isackson PJ (1994) Basic fibroblast growth factor mRNA is increased in forebrain neurons and glia following recurrent limbic seizures. Mol Brain Res 21:190-205.

Gall C, Lauterborn J, Guthrie K (1995) In situ hybridization as a sensitive measure of activity dependent neuronal gene expression. In: Autoradiography and correlative imaging (Strumpf WE, Solomon HF, eds), pp 379-399. San Diego: Academic.

Ghosh A, Carnahan J, Greenberg ME (1994) Requirement for BDNF in activity-dependent survival of cortical neurons. Science 263:1616-1623.

Hayes VY, Murray KD, Isackson PJ (1995) Differential regulation of BDNF transcripts through a calcium/calmodulin-dependent protein kinase pathway. Soc Neurosci Abstr 21:1046.

Hengerer B, Lindholm D, Heumann R, Ruther U, Wagner EF, Thoenen $\mathrm{H}$ (1990) Lesion-induced increase in nerve growth factor mRNA is mediated by $c$-fos. Proc Natl Acad Sci USA 87:3899-3903.

Hughes P, Beilharz E, Gluckman P, Dragunow M (1993) Brain-derived neurotrophic factor is induced as an immediate early gene following $N$-methyl-D-aspartate receptor activation. Neuroscience 57:319-328.

Humpel C, Wetmore C, Olson L (1993) Regulation of brain-derived neurotrophic factor messenger RNA and protein at the cellular level in pentylenetetrazol-induced epileptic seizures. Neuroscience 53:909-918.

Hyman C, Juhasz M, Jackson C, Wright P, Ip NY, Lindsay RM (1994) Overlapping and distinct actions of the neurotrophins BDNF, NT-3, and NT-4/5 on cultured dopaminergic and GABAergic neurons of ventral mesencephalon. J Neurosci 14:335-347.

Ip NY, Li Y, Yancopoulos GD, Lindsay RM (1993) Cultured hippocampal neurons show responses to BDNF, NT-3, and NT-4 but not NGF. J Neurosci 13:3394-3405.

Isackson PJ, Murray K, Huntsman M, Gall CM (1991) BDNF mRNA expression is increased in adult rat forebrain after limbic seizures: temporal patterns of induction distinct from NGF. Neuron 6:937-948.

Kokaia Z, Metsis M, Kokaia M, Bengzon J, Elmér E, Smith M-L, Timmusk T, Siesjö BK, Persson H, Lindvall O (1994a) Brain insults in rats induce increased expression of the BDNF gene through differential use of multiple promoters. Eur J Neurosci 6:587-596.

Kokaia Z, Othberg A, Kokaia M, Lindvall O (1994b) BDNF makes cultured dentate granule cells more resistant to hypoglycaemic damage. NeuroReport 5:1241-1224.

Koliatsos VE, Clatterbuck RE, Winslow JW, Cayouette MH, Price DL (1993) Evidence that brain-derived neurotrophic factor is a trophic factor for motor neurons in vivo. Neuron 10:359-367.

Lauterborn JC, Tran TM, Isackson P, Gall CM (1993) NGF mRNA is expressed by GABAergic neurons in rat hippocampus. NeuroReport 5:273-276.

Lauterborn JC, Isackson PJ, Gall CM (1994) Cellular localization of NGF and NT-3 mRNAs in postnatal rat forebrain. Mol Cell Neurosci 5:46-62.

Leibrock J, Lottespeich AH, Hofer M, Hengerer B, Masiakowski P, Thoenen H, Barde Y (1989) Molecular cloning and expression of brain-derived neurotrophic factor. Nature 341:149-152.

Leingärtner A, Lindholm D (1994) Two promoters direct transcription of the mouse NT-3 gene. Eur J Neurosci 6:1149-1159.

Lindefors N, Ernfors P, Falkenberg T, Persson H (1992) Septal cholinergic afferents regulate expression of brain-derived neurotrophic factor and $\beta$-nerve growth factor mRNA in rat hippocampus. Exp Brain Res $88: 78-90$.

Lindvall O, Kokaia Z, Bengzon J, Elmér E, Kokaia M (1994) Neurotrophins and brain insults. Trends Neurosci 17:490-496.

Metsis M, Timmusk T, Arenas E, Persson H (1993) Differential usage of multiple brain-derived neurotrophic factor promoters in the rat brain following neuronal activation. Proc Natl Acad Sci USA 90:8802-8806.

Mocchetti I, De Bernadi M, Szekely A, Alho H, Brooker G, Costa E (1989) Regulation of nerve growth factor biosynthesis by $\beta$-adrenergic receptor activation in astrocytoma cells: a potential role of c-Fos protein. Proc Natl Acad Sci USA 86:3891-3895.

Motulsky H (1995) Intuitive biostatistics. New York: Oxford UP.

Nakao N, Kokaia Z, Odin P, Lindvall O (1995) Protective effects of BDNF and NT-3 but not PDNF against hypoglycemic injury to cultured striatal neurons. Exp Neurol 131:1-10.

Nakayama M, Gahara Y, Kitamura T, Ohara O (1994) Distinctive four promoters collectively direct expression of brain-derived neurotrophic factor gene. Mol Brain Res 21:206-218.

Nawa H, Carnahan J, Gall C (1995) BDNF protein measured by a novel enzyme immunoassay in normal brain and after seizure: partial disagreement with mRNA levels. Eur J Neurosci 7:1527-1535.

Omae E, Katsumata T, Sakuma M, Furukawa Y, Furukawa S (1994) Prolonged alkylcatechol-induced expression of c-jun proto-oncogene followed by elevation of NGF mRNA in cultured astroglial cells. J Neurosci Res 39:290-297.

Patterson SL, Grover LM, Schwartzkroin PA, Bothwell M (1992) Neurotrophin expression in rat hippocampal slices-a stimulus paradigm inducing LTP in CA1 evokes increases in BDNF and NT-3 messenger RNAs. Neuron 9:1081-1088.

Qian Z, Gilbert ME, Colicos MA, Kandel ER, Kuhl D (1993) Tissueplasminogen activator is induced as an immediate-early gene during seizure, kindling and long-term potentiation. Nature 361:453-457.

Rivera S, Gold S, Gall CM (1994) Interleukin-1 $\beta$ increases basic fibroblast growth factor mRNA expression in adult rat brain and organotypic hippocampal cultures. Mol Brain Res 27:12-26.

Sassone-Corsi P, Sisson JC, Verma IM (1988) Transcriptional autoregulation of the proto-oncogene fos. Nature 334:314-319.

Selby MJ, Edwards R, Sharp F, Rutter WJ (1987) Mouse nerve growth factor gene: structure and expression. Mol Cell Biol 7:3057-3064.

Spina MB, Squinto SP, Miller J, Lindsay RM, Hyman C (1992) Brainderived neurotrophic factor protects dopamine neurons against 6-hydroxydopamine and $N$-methyl-4-phenylpyridinium ion toxicity: involvement of the glutathione system. J Neurochem 59:99-106.

Squinto SP, Stitt TN, Aldrich TH, Davis S, Bianco SM, Masiakowski P, Furth ME, Valenzuela DM, DiStefano PS, Yancopoulos GD (1991) trkB encodes a functional receptor for brain-derived neurotrophic factor and neurotrophin-3 but not nerve growth factor. Cell 65:885-893.

Stoppini S, Buchs PA, Muller D (1991) A simple method for organotypic cultures of nervous tissue. J Neurosci Methods 37:173-182.

Timmusk T, Palm K, Metsis M, Reintam T, Paalme V, Saarma M, Persson H (1993) Multiple promoters direct tissue-specific expression of the rat BDNF gene. Neuron 10:475-489.

Vigé X, Costa E, Wise BC (1991) Mechanism of nerve growth factor mRNA regulation by interleukin-1 and basic fibroblast growth factor in primary cultures of rat astrocytes. Mol Pharmacol 40:186-192.

Whittemore SR, Friedman PL, Larhammar D, Persson H, GonzalesCarvajal M, Holets VR (1988) Rat $\beta$-nerve growth factor sequence and site of synthesis in the adult hippocampus. J Neurosci Res 20:403-410.

Wion D, Grogan DM, Houlgatte R, Brachet P (1990) Phorbol 12 myristate 13-acetate (PMA) increases the expression of nerve growth factor (NGF) gene in mouse L-929 fibroblasts. FEBS Lett 262:42-44.

Zafra F, Castrén E, Thoenen H, Lindholm D (1991) Interplay between glutamate and gamma-amino butyric acid transmitter systems in the physiological regulation of brain-derived neurotrophic factor and nerve growth factor synthesis in hippocampal neurons. Proc Natl Acad Sci USA 88:10037-10041.

Zafra F, Lindholm D, Castrén E, Hartikka J, Thoenen H (1992) Regulation of brain-derived neurotrophic factor and nerve growth factor mRNA in primary cultures of hippocampal neurons and astrocytes. J Neurosci 12:4793-4799. 